OPEN ACCESS

Edited by:

Junjie Xiao,

Shanghai University, China

Reviewed by:

Dalei Wu,

Shandong University, China

Liang Zhang,

Shanghai Jiao Tong University, China

${ }^{*}$ Correspondence:

Lei Feng

feng2008lei@163.com

Tingting Zhou

tingtingchou@126.com

tThese authors have contributed equally to this work and share first authorship

Specialty section:

This article was submitted to

General Cardiovascular Medicine,

a section of the journal

Frontiers in Cardiovascular Medicine

Received: 22 March 2021 Accepted: 09 April 2021

Published: 05 May 2021

Citation:

Yang S, Wang Z, Guo M, Du M, Wen X, Geng L, Yu F, Liu L, Li Y

Feng $L$ and Zhou $T$ (2021)

UPLC-MS-Based Serum

Metabolomics Reveals Potential

Biomarkers of Ang II-Induced Hypertension in Mice.

Front. Cardiovasc. Med. 8:683859.

doi: 10.3389/fcvm.2021.683859

\section{UPLC-MS-Based Serum} Metabolomics Reveals Potential Biomarkers of Ang II-Induced Hypertension in Mice

\author{
Shaying Yang ${ }^{\dagger}$, Zhiwei Wang ${ }^{\dagger}$, Mengting Guo, Mengfan Du, Xin Wen, Li Geng, Fan Yu, \\ Liangliang Liu, Yanting Li, Lei Feng * and Tingting Zhou*
}

Laboratory of Cardiovascular Research, School of Medicine, Jiangnan University, Wuxi, China

Hypertension is caused by polygenic inheritance and the interaction of various environmental factors. Abnormal function of the renin-angiotensin-aldosterone system (RAAS) is closely associated with changes in blood pressure. As an essential factor in the RAAS, angiotensin II (Ang II) contributes to vasoconstriction and inflammatory responses. However, the effects of overproduction of Ang II on the whole body-metabolism have been unclear. In this study, we established a hypertensive mouse model by micro-osmotic pump perfusion of Ang II, and the maximum systolic blood pressure reached $140 \mathrm{mmHg}$ after 2 weeks. By ultra-performance liquid chromatography-quadrupole time-of-flight mass spectrometry, the metabolites in the serum of hypertensive model and control mice were analyzed. Partial least squares discriminant analysis (PLS-DA) in both positive and negative ionization modes showed clear separation of the two groups. Perfusion of Ang II induced perturbations of multiple metabolic pathways in mice, such as steroid hormone biosynthesis and galactose metabolism. Tandem mass spectrometry revealed 40 metabolite markers with potential diagnostic value for hypertension. Our data indicate that non-targeted metabolomics can reveal biochemical pathways associated with Ang II-induced hypertension. Although researches about the clinical use of these metabolites as potential biomarkers in hypertension is still needed, the current study improves the understanding of systemic metabolic response to sustained release of Ang II in hypertensive mice, providing a new panel of biomarkers that may be used to predict blood pressure fluctuations in the early stages of hypertension.

Keywords: hypertension, LC-MS, angiotensin II, metabolomics, serum metabolites, biomarkers, mice

\section{INTRODUCTION}

Hypertension is a common cardiovascular disease and the leading risk factor for both cardiovascular and cerebrovascular events. It can cause functional or organic lesions of the heart, brain, blood vessels, kidneys, and other organs, contributing to a significant cause of disability and death (1). The incidence and development of hypertension are affected by both genetic and environmental factors (2). In recent studies, $60 \%$ of the main factors leading to hypertension have been associated with metabolic abnormalities, while $80 \%$ of hypertensive patients have various forms of metabolic disorder (3). 
Ang II increases systemic blood pressure and glomerular capillary pressure. It is directly involved in renal arteriosclerosis and causes kidney damage (4). It also increases the pressure in the glomeruli and contracts mesangial cells, leading to an increase in the selective permeability to urine proteins. Clinical and experimental studies have shown that it regulates the processes of inflammation and fibrosis contributing to kidney pathogenesis through activating growth factors associated with fibrosis (5). The clinical manifestations of hypertension and kidney damage are persistent hypertension accompanied by persistent trace or mild-to-moderate proteinuria, and impaired renal function (i.e., increased creatinine and urea nitrogen) (6). Ang II-induced hypertension leads to the hypertrophy of smooth muscle cells and to increases in the expression of their specific markers, eventually leading to thickening of the arterial media and increasing vascular resistance (7).

A study revealed that Ang II induction increases thromboxane production in mice (8), and another indicated that prolonged Ang II-induced hypertension and massive blood-brain barrier leakage, microglia activation, myelin loss, and memory dysfunction are associated with stroke compared with control mice (9).

High-throughput full-spectrum analysis of metabolites provides an opportunity to assess disease severity, restored metabolic pathways, and homeostasis $(10,11)$. Identifying the disturbed biochemical pathways helps to understand changes in body components during the development of hypertension. Therefore, we aimed to find the endogenous molecular metabolites regulating the blood vessels of mice during the induction by Ang II by analyzing the metabolic spectrum that can be used as a marker for early blood pressure fluctuations.

Metabolomics based on liquid chromatography-mass spectrometry (LC-MS) is an effective method for the metabolic profiling of biological systems (12). LC-MS analysis has higher sensitivity and a more comprehensive polarity range than NMR spectroscopy $(13,14)$. In the current study, the UPLC-QTOF/MS (ultra-performance liquid chromatography-quadrupole time-of-flight mass spectrometry) platform was used to analyze serum samples from control and Ang II-induced hypertensive mice to explore the differential metabolites of hypertension induced by slow-release Ang II. We identified $>40$ different metabolites involved in $>20$ metabolic pathways in the Ang II mice.

\section{METHODS AND MATERIALS}

\section{Animals and Sample Collection}

All animal experiments were performed in accordance with the laboratory animal guidelines and with the approval of the

Abbreviations: RAAS, renin-angiotensin-aldosterone system; Ang II, angiotensin II; UPLC-Q-TOF/MS, ultra-performance liquid chromatography-quadrupole time-of-flight mass spectrometry; LC-MS, liquid chromatography-mass spectrometry; QC, quality control; ESI+, electrospray ionization positive ion mode; ESI-, electrospray ionization negative ion mode; RSD, relative standard deviation; PCA, principal component analysis; PLS-DA, partial least squaresdiscriminant analysis; ABC, ATP binding cassette membrane transporter; PPAR, peroxisome proliferators-activated receptor.
Animal Experimentation Ethics Committee, Jiangnan University (License No: JN. No 20190930c1000120[232]). The male C57BL/6J mice used in the experiments were provided by the Institute of Model Animal Research of Nanjing University, and were reared in a specific pathogen-free environment. The average body weight was $\sim 23 \mathrm{~g}$. The mice were divided into two groups (Ang II and control groups) of 10 mice each. Mice were infused subcutaneously with Ang-II (Sigma, $600 \mathrm{ng} / \mathrm{kg} / \mathrm{min}$ ), or vehicle (0.9\% saline) for 19 days using osmotic pumps (Alzet) (15). Venous blood was collected from the retro-orbital venous plexus using a blood collection capillary.

\section{Measurement of Blood Pressure}

We used a non-invasive blood pressure meter (IITC Life Science) to measure the blood pressure of the mice.

\section{Sample Preparation}

Two hundred microliters of each sample was placed in a new Eppendorf tube, to which was added $800 \mu \mathrm{L}$ of methanol/water $(\mathrm{v} / \mathrm{v}=8: 1)$ pre-cooled at $-20^{\circ} \mathrm{C}$ for $>0.5 \mathrm{~h}$; then iron beads were added and the samples were lysed at $60 \mathrm{~Hz}$ for $5 \mathrm{~min}$. After each sample is mixed in equal volume, it is used as a quality control (QC) sample.

\section{Metabolomic Analysis Based on LC-MS/MS}

An ACQUITY UPLC BEH C18 column $(100 \times 2.1 \mathrm{~mm}, 1.7 \mu \mathrm{m}$, Waters Corp., UK) was used for chromatographic separation. The column temperature was $50^{\circ} \mathrm{C}$ and the flow rate was 0.4 $\mathrm{ml} / \mathrm{min}$, where mobile phase A was water and $0.1 \%$ formic acid, and mobile phase $\mathrm{B}$ was methanol and $0.1 \%$ formic acid. The sample was eluted with the following gradient: $0-2 \mathrm{~min}, 100 \%$ A; 2-11 $\min , 0-100 \%$ B; $11-13 \mathrm{~min}, 100 \% \mathrm{~B}$; $13-15 \min 0-100 \%$ A. For the small molecules eluted from the column, the highresolution tandem mass spectrometry using Xevo G2-XS QTOF (Waters, UK) was used to collect positive and negative ions. In electrospray ionization positive ion mode (ESI+), the capillary voltage was $3 \mathrm{kV}$ and the cone voltage $40 \mathrm{~V}$; in ESI negative ion mode (ESI-), the capillary and cone voltages were $1 \mathrm{kV}$ and $40 \mathrm{~V}$. The mass spectrometry data were acquired in Centroid MSE mode. The TOF mass range was from 50 to $1,200 \mathrm{Da}$ and the scan time was $0.2 \mathrm{~s}$. For the MS/MS detection, all precursors were fragmented using $20-40 \mathrm{eV}$, and the scan time was $0.2 \mathrm{~s}$. During the acquisition, the LE signal was acquired every $3 \mathrm{~s}$ to calibrate the mass accuracy. Meanwhile, the quality control (QC) samples were collected every 10 samples to evaluate the stability of the instrument during the sample collection process.

\section{Data Processing, Mass Spectrometric Identification, and Statistical Analysis}

Peak extraction was mainly achieved using the software Progenesis QI (version 2.2), including peak alignment, peak extraction, normalization, deconvolution, and compound identification. See the previous report for details (16). The results show the mean \pm SEM. Comparisons among groups were made using ANOVA or unpaired Student's $t$-test, with $P<0.05$ as the threshold for a significant difference. 

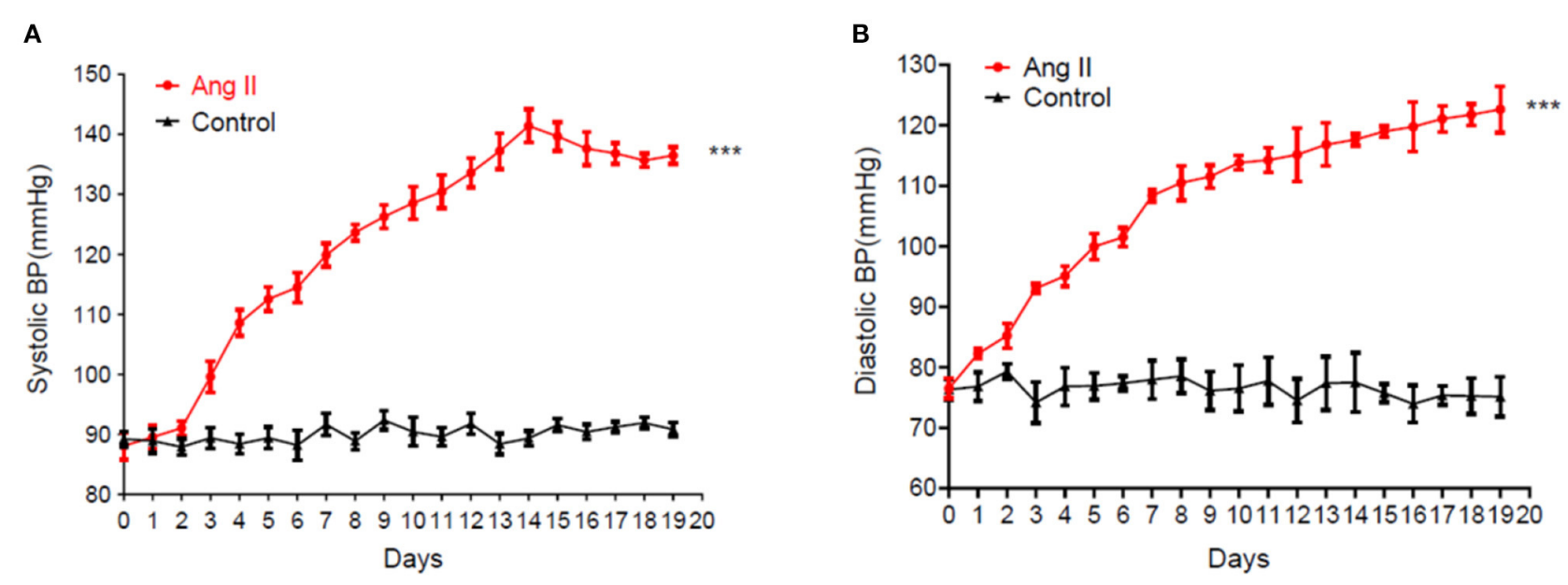

FIGURE 1 | Sustained rise of systolic blood pressure $\mathbf{( A )}$ and diastolic blood pressure $\mathbf{( B )}$ in mice induced by the continuous release of Ang $\|$ (data are the mean \pm SEM, $n=10,{ }^{* \star *} P<0.001$ vs. Control, two-way ANOVA).

\section{Metabolite Annotation and Pathway Analysis}

Metabolites were identified by matching the exact molecular mass data $(\mathrm{m} / \mathrm{z})$ of the samples against METLIN (http:// metlin.scripps.edu/) and the Human Metabolome Database (http://www.hmdb.ca/) with 10-ppm accuracy (17, 18). We quantitatively mapped the different metabolites to the reference paths in the online Kyoto Encyclopedia of Genes and Genomes database (https://www.kegg.jp/kegg/pathway.html). Statistically significant enrichment pathways were evaluated by the hypergeometric test adjusted by the false discovery rate $(P<0.05)$.

\section{RESULTS}

\section{Mouse Model of Ang II-Induced Hypertension}

Blood pressure recorded in the Ang II model significantly and continuously rose from day 5 (Figure 1). On day 17, the systolic blood pressure in the Ang II group was $140 \mathrm{mmHg}$ while the controls remained at $\sim 89 \mathrm{mmHg}$. Therefore, this model of hypertension induced by slow-release Ang II was successful.

\section{Metabolites Differ Between Control and Ang II-Induced Hypertensive Mice}

None of the QC sample chromatograms showed significant retention time drift. We measured 5,904 ions in ESI+ mode and 6,937 in ESI- mode (Figures 2A,B). After elimination and filling in, 4,557 and 5,773 ions were finally obtained. The QC samples were tightly clustered, and were significantly separate from the test samples, indicating that the LC-MS/MS analysis platform had high stability and reproducibility (16) (Figures 2C,D). We further used three-dimensional principal component analysis (PCA) scatter plots to evaluate changes in the metabolite profile of mice during the development of Ang II-induced hypertension. The ordinary "unsupervised" analysis was unable to distinguish between the Ang II and control groups (Figures 2E,F). However, the use of partial least-squares discriminant analysis built an excellent regression model. The three-dimensional scatter diagram showed that the Ang II and control groups were significantly separated (Figures 3A,B), showing different metabolic phenotypes. This indicated that the sustained release of Ang II leads to metabolic disorders in mice. We selected the top 20 serum metabolites that met the variable importance in the projection threshold $(\mathrm{VIP}>1)$ and Student's $t$-test $(P<0.05)$ criteria in the ESI+ and ESI- modes. Volcano maps based on $P$-values and one-dimensional test multiple changes (Figures 3C,D) and heat maps based on differences in metabolite abundance also showed clear separation of the Ang II and control groups (Figures 3E,F).

In ESI+ mode, contents of 4-Hydroxy-6-methylpretetramide, 6-Phospho-D-gluconate and Aminopentol considerably increased, and Ephedroxane and Bellendine obviously decreased in Ang II-induced hypertensive mice (Table 1). Likewise, variance in the production of $\mathrm{N}$ (omega)-Nitro-L-arginine, Deoxypeganine and Hinokitiol glucoside was also observed between Ang II and control groups in ESI- mode (Table 2).

\section{Metabolic Pathway Disorders}

The serum metabolites of the mice made hypertensive by Ang II were significantly different from the control group. Compared with control mice, 581 differential metabolites were obtained under ESI+ mode and 530 under ESImode (Supplementary Materials). Search of a mass-based metabolomics database showed that metabolite ions detected under the ESI+ and ESI- modes included disaccharides, glycerophospholipids, amino-acids, sphingolipids, fatty acyl groups, acylcarnitines, and other organic compounds. Here, the 
A
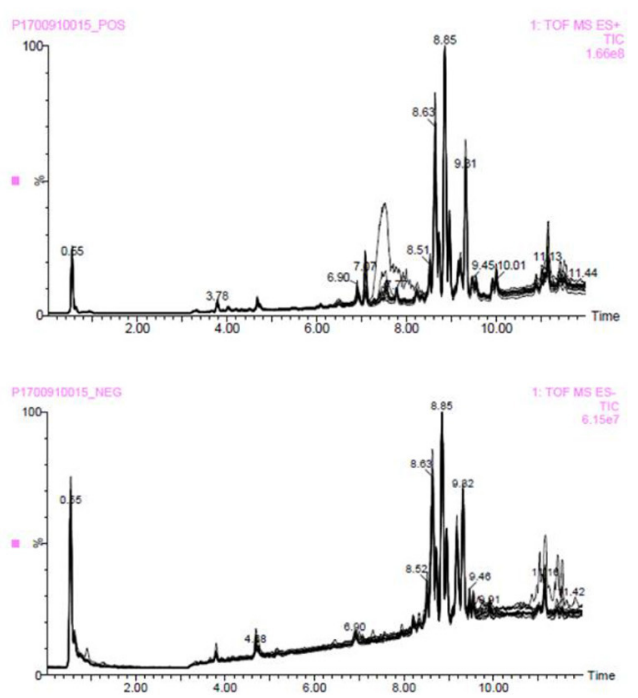

C

batch -1 class $\rightarrow$ Ang $I I \rightarrow$ Control $\rightarrow Q C$

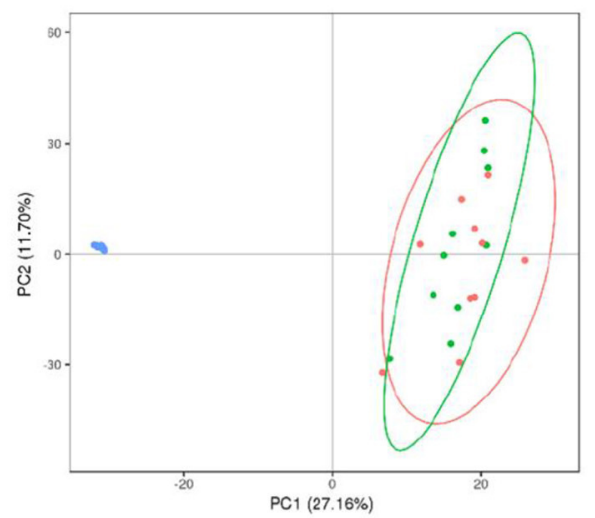

E

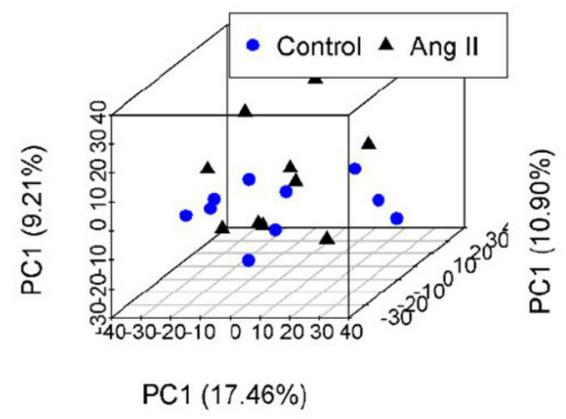

B
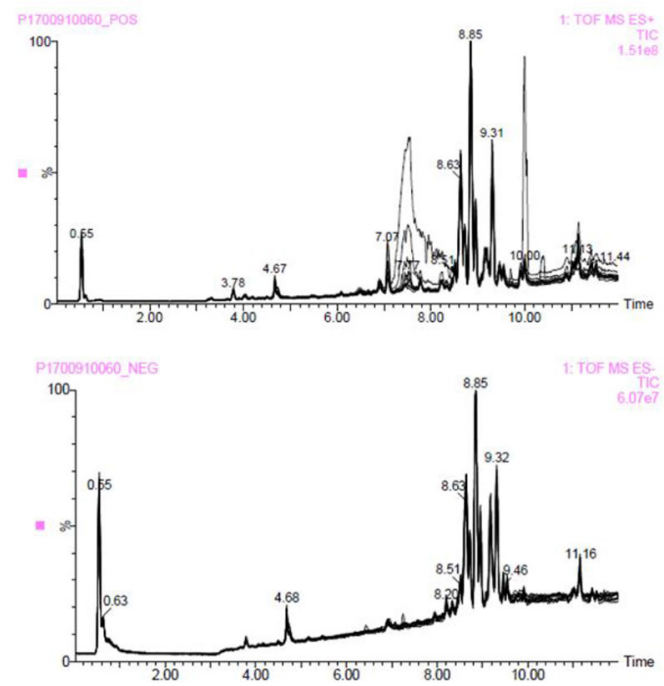

D

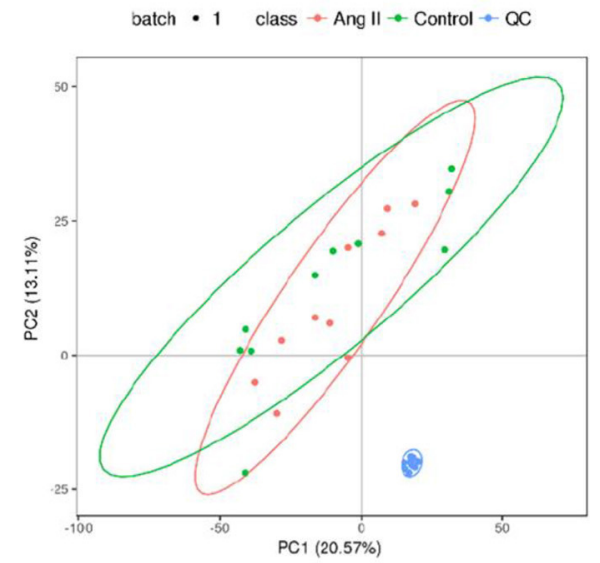

$\mathbf{F}$

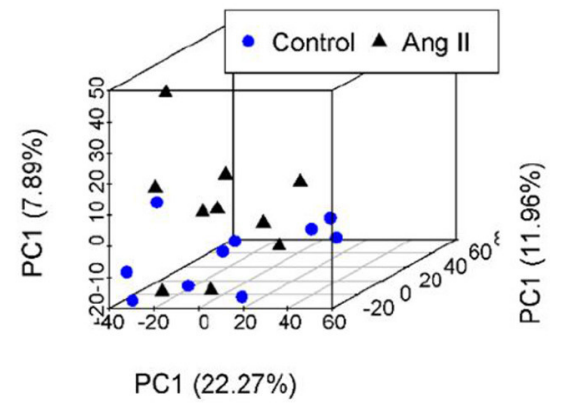

FIGURE 2 | (A,B) Total ion chromatograms of QC samples in Control (A) and Ang Il groups (B) in ESI+ and ESI- mode. (C,D) Plots of PCA scores for serum samples from test mice and QC samples showing metabolites obtained in ESI+ mode (C) and ESI- mode (D). (E,F) Scatter plots of PCA scores of metabolites from the LC-MS/MS fingerprints in ESI+ mode (E) and ESI- mode (F). 
A
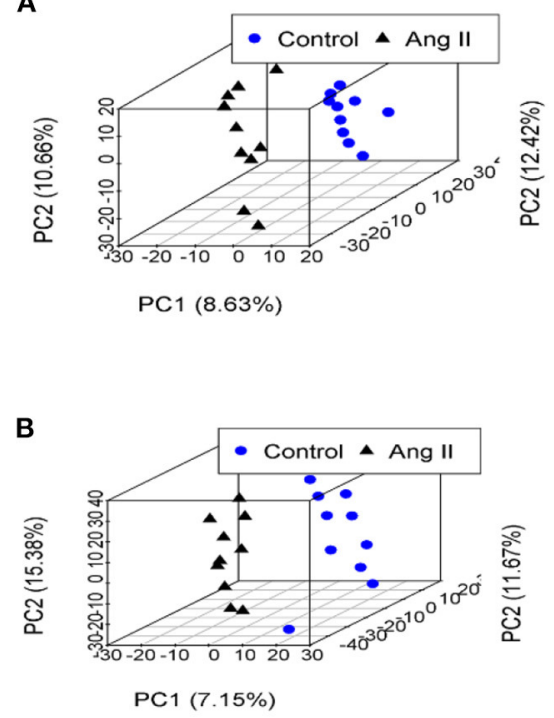

C

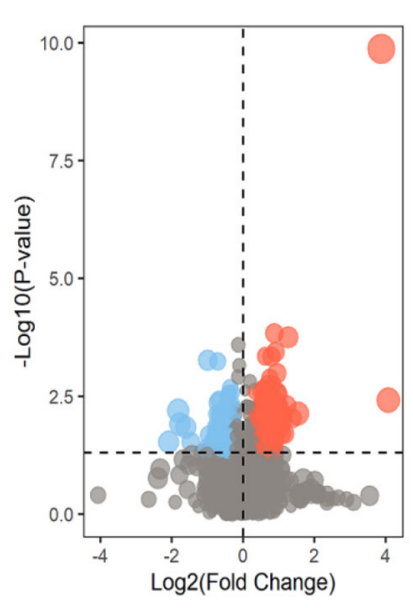

D

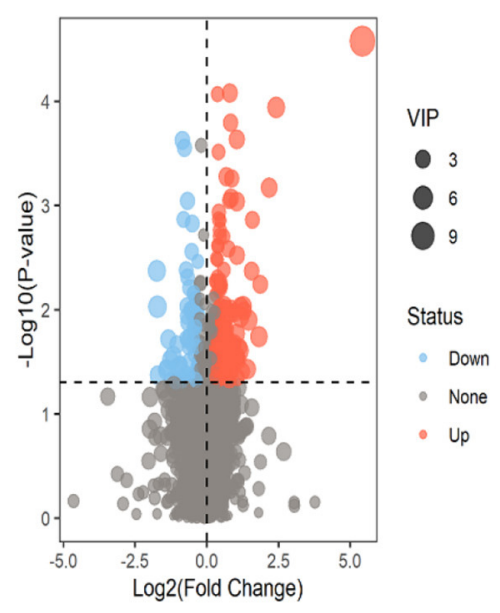

E

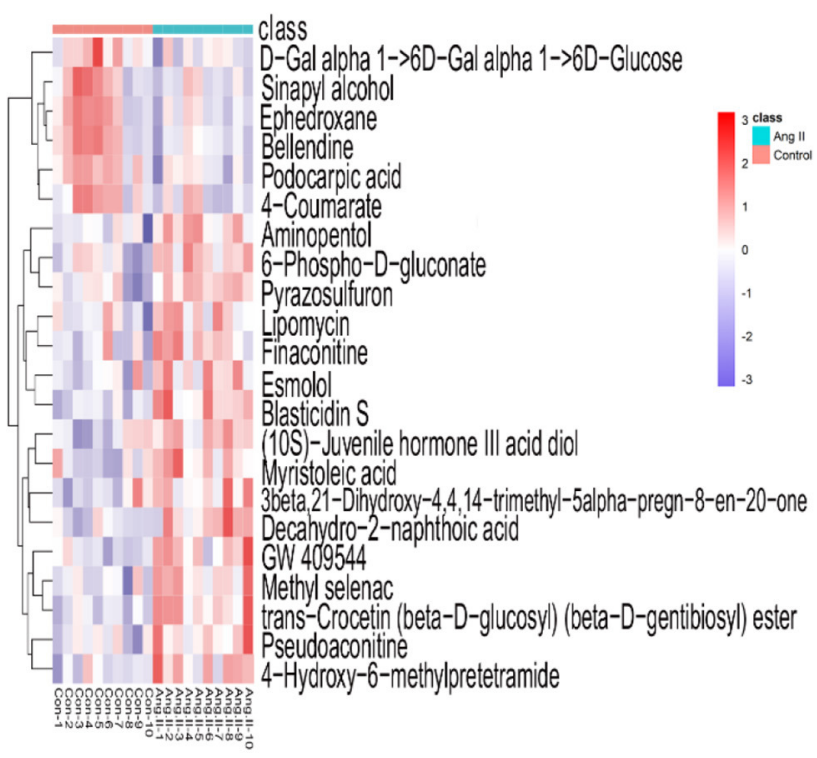

F

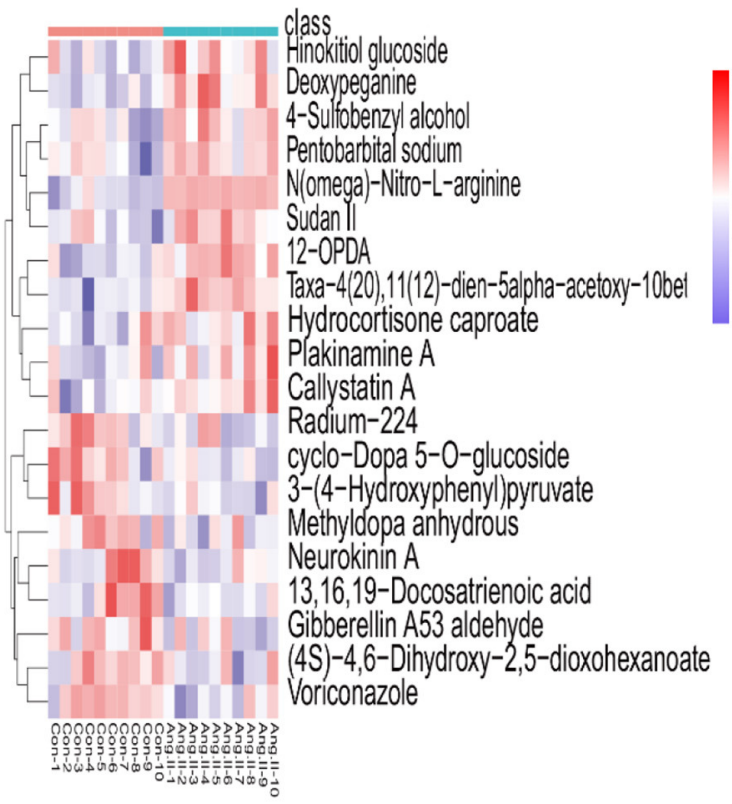

FIGURE 3 | (A,B) 3-D plots of scores from partial least-squares discriminant analysis based on the metabolic profiling data from the plasma of Ang II-induced hypertensive mice and healthy (control) mice in ESI+ (A) and ESI- mode (B) (black triangles, Ang II-induced hypertensive mice; blue circles, control mice). (C,D) Volcano plots based on $P$-values and fold-changes of single-dimensional tests in ESI+ mode (C) and ESI- mode (D). (E,F) Heatmaps of the differential metabolites for Ang II vs. control in ESI+ mode (E) and ESI- mode (F). 
TABLE 1 | Top 20 differential serum metabolites between Ang II-induced hypertension mice and control mice in ESI+ mode.

\begin{tabular}{|c|c|c|c|c|}
\hline Compound & $P$-value & Regulation & Fold change & Retention time/min \\
\hline (10S)-Juvenile hormone III acid diol & 0.009 & Up & 2.001 & 5.587 \\
\hline 3beta,21-Dihydroxy-4,4,14-trimethyl-5alpha-pregn-8-en-20-one & 0.020 & Up & 2.249 & 7.477 \\
\hline 4-Hydroxy-6-methylpretetramide & 0.004 & Up & 16.918 & 6.664 \\
\hline 6-Phospho-D-gluconate & 0.007 & Up & 2.917 & 4.511 \\
\hline Blasticidin S & 0.0001 & Up & 1.839 & 3.827 \\
\hline D-Gal alpha 1->6D-Gal alpha 1->6D-Glucose & 0.030 & Down & 0.362 & 0.633 \\
\hline Ephedroxane & 0.030 & Down & 0.237 & 4.262 \\
\hline Esmolol & 0.016 & Up & 2.027 & 3.691 \\
\hline Finaconitine & 0.008 & Up & 2.084 & 4.055 \\
\hline Myristoleic acid & 0.005 & Up & 2.324 & 8.555 \\
\hline Podocarpic acid & 0.015 & Down & 0.331 & 3.563 \\
\hline Pseudoaconitine & 0.011 & Up & 2.184 & 4.725 \\
\hline Pyrazosulfuron & 0.008 & Up & 2.202 & 4.860 \\
\hline trans-Crocetin (beta-D-glucosyl) (beta-D-gentibiosyl) ester & 0.0002 & Up & 2.410 & 4.668 \\
\hline
\end{tabular}

TABLE 2 | Top 20 differential serum metabolites between Ang II-induced hypertension mice and control mice in ESI- mode.

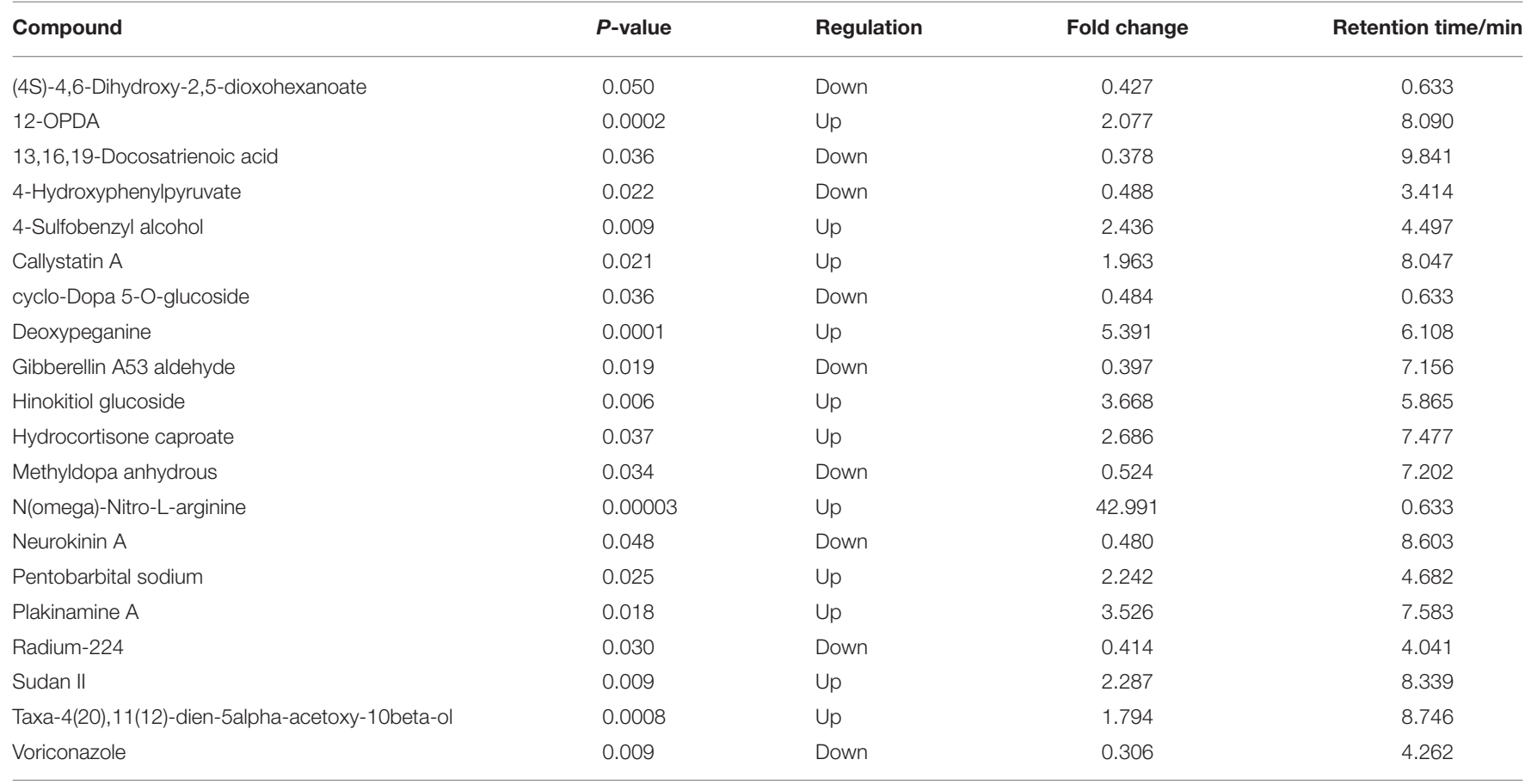

top 20 metabolites and their regulatory changes under the two ion modes were identified as potential biomarkers in developing hypertension (Tables 1, 2). In addition, these metabolites mapped to $>20$ metabolic pathways, mainly sugar and linoleic acid metabolism, carbohydrate digestion and absorption, ATP binding cassette $(\mathrm{ABC})$ membrane transporter transport protein, peroxisome proliferator-activated receptor (PPAR), and hypoxiainducible factor-1 signaling pathways (Figure 4). 

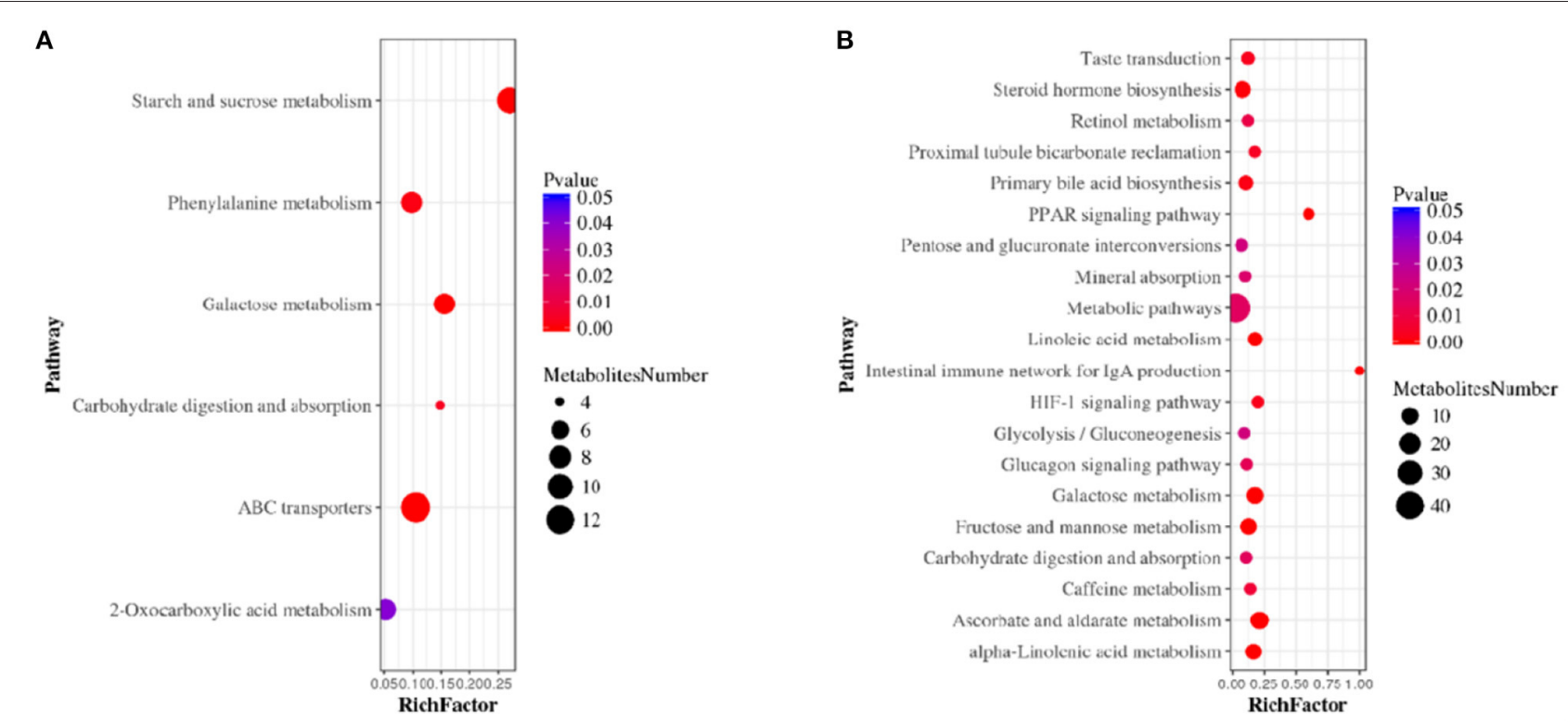

FIGURE 4 | Metabolic pathway enrichment analysis in ESI+ mode (A) and ESI- mode (B). The size of each circle represents the number of metabolites enriched in the pathway.

\section{DISCUSSION}

The renin-angiotensin-aldosterone system (RAAS) is one of the systems closely related to vasomotor and sodium-water metabolism in vivo, which plays crucial roles in cardiovascular physiology and pathophysiology $(19,20)$. In the RAAS, the angiotensin converting enzyme (ACE) generates Ang II, which has high bioactivity and powerful vasoconstrictor effect. It is wellknown that a variety of cardiovascular risk factors are closely associated with Ang II (21-23). The ability of Ang II to elevate blood pressure is $10 \sim 40$ times powerful than adrenaline (24). Ang II raises blood pressure through multiple factors, mainly through stimulating zona glomerulosa of the adrenal gland, promoting aldosterone secretion and sodium-water retention $(20,25-27)$. Besides, it enhances noradrenaline release from sympathetic nerve endings (28). Meanwhile, elevation of Ang II content promotes oxidative stress and endothelial dysfunction, and plays a crucial role in atherosclerosis $(29,30)$. Vascular damage, regulated with Ang II, is also dependent on the gut microbiome (31). It is noticed that a significant positive correlation between Ang II level and left ventricular hypertrophy in the hypertensive patients diagnosed without any treatment $(32,33)$. Plasma Ang II level is significantly correlated to the end diastolic interventricular septal diameter (IVSDd) in essential hypertension (34). Taken together, due to the multifactorial roles played by Ang II in the course of hypertension, it has been used in many studies to construction of hypertensive models in mice $(35,36)$.

In this study, we analyzed the serum metabolites of Ang II-induced hypertensive mice based on an LC-MS/MS platform. Our results showed that the slow release of Ang II induces metabolomics changes in mice, promoting the development of hypertension. According to previous research reports on Ang II-induced hypertension (37), the body weight of mice will decrease significantly during the sustained release of Ang II, which may be related to metabolic disorders in the body.

Ang II is a critical factor in hypertension, diabetes, and aging, and it induces many metabolic pathway disorders. Hypertension and diabetes are considered to be the main components of metabolic syndrome, sharing a common pathogenesis according to a large number of basic and clinical studies (38-40). About 60$70 \%$ of diabetic patients have hypertension (41), and hypertensive patients have abnormal glucose metabolism. Consistent with this, our results showed that Ang II-induced hypertension in mice was accompanied by evident glucose metabolism disorder. A significant increase in 6-phosphate-d-gluconate and decreases in maltose, lactose, and other disaccharides was found in the Ang II group. The analysis of metabolite pathway enrichment showed a disturbed glucagon signal pathway, consistent with the phenomenon of hyperinsulinemia in hypertensive patients.

In recent years, PPARs have been closely associated with energy metabolism, cell differentiation, proliferation, apoptosis, and the inflammatory response (42-44). Ang II increases the permeability of cerebral vascular endothelium via type 1 receptors, disrupts the membrane distribution of zonula occludens-1 and vascular endothelial-cadherin on cerebral vascular endothelium, decreases the total levels of junctional adhesion molecule-A and major facilitator superfamily domaincontaining protein $2 \mathrm{a}$, and increases caveolin 1 accompanied by the de-phosphorylation of PPAR $\alpha$. PPAR $\alpha$ agonists improve the endothelial permeability caused by Ang II (45). Interestingly, in ESI- mode, we found that the levels of three metabolites [9-cisretinoic acid, 9(S)-hydroxyoctadecadienoic acid (HODE), and 13(S)-HODE] are closely associated with the PPAR signaling 
pathway. After 2 weeks of Ang II induction in mice, the content of 9-cis-retinoic acid, an active metabolite of vitamin A, increases significantly. The content of 9-cis-retinoic acid in the serum of Ang II-induced hypertensive mice was 1.42 times compared to control mice $(P=0.03$; VIP $=1.66)$. 9cis-Retinoic acid is an active retinoid that regulates expression of retinoid responsive genes (46). 9-cis-Retinoic mediates gene transcription acting through the retinoic acid receptors (RARs) and the retinoid X receptors (RXRs) in cells (47). In addition to PPARs, RXRs are also an essential heterodimeric partner for other subclass I nuclear receptors, such as the farnesoid $\mathrm{X}$ receptor (FXR), thyroid hormone receptors, the vitamin $\mathrm{D}$ receptor and the liver X receptor (LXR) (48-51). However, the transcriptional complex formed by RXRs and PPARs plays a critical role in energy balance, such as glucose homeostasis, fatty acid handling and triglyceride metabolism (52). The PPAR-RXR transcriptional complex also participates in inflammatory and vascular responses in endothelial and vascular smooth muscle cells directly (52-54). It has been suggested that RXR regulates the growth and differentiation of normal and malignant cells, and inhibits the prostaglandin expression of endoperoxide-2 (55). However, retinoic acid is a toxin that can bring about fracture, skin injury and swelling, serum calcium elevation, limited dose hyperlipidemia (cholesterol and triglyceride elevation), and hypothyroidism (56). Ang II contributes to an increase in the content of two HODEs that have been used as biomarkers for assessing oxidative status (57).

The $\mathrm{ABC}$ is an outflow promoter of phospholipid and cholesterol, playing an essential role in the development of atherosclerosis and arterial hypertension. ABCA1 mediates the first step of reverse cholesterol transport by transporting excess cholesterol in peripheral tissues to the liver for excretion (58). Recent evidence has shown that the expression of ABCA1 is significantly decreased in patients with hypertension, and the outflow of cholesterol to apo-A1 leads to increased carotid intima-media thickness, and promotes arterial hypertension (59). Interestingly, in ESI+/ESI- modes, we identified 19 differential metabolites that were enriched in the metabolic pathway of the $\mathrm{ABC}$ transporter. These substances may affect lipid metabolism and increase blood vessel wall pressure by interfering with the flow of cholesterol from monocytes, macrophages, and the liver.

In this study, we found changes in the serum metabolome treated with Ang II in mice, providing new clues for the further study of the pathophysiological mechanisms in hypertension. Our non-targeted metabolomics research identified specific differences related to carbohydrate, lipid, and carbohydrate metabolism in hypertension. These results improve the

\section{REFERENCES}

1. Shenasa M, Shenasa H. Hypertension, left ventricular hypertrophy, and sudden cardiac death. Int $J$ Cardiol. (2017) 237:603. doi: 10.1016/j.ijcard.2017.03.002

2. Kato N, Takeuchi F, Tabara Y, Kelly TN, Go MJ, Sim X, et al. Meta-analysis of genome-wide association studies identifies common variants associated with blood pressure variation in east Asians. Nat Genet. (2011) 43:5318. doi: $10.1038 /$ ng. 834 understanding of systemic metabolic response to sustained release of Ang II in hypertensive mice, providing a new panel of biomarkers that may be used to predict blood pressure fluctuations in the early stages of hypertension, although researches about the clinical use of these metabolites as potential biomarkers in hypertension is still needed.

\section{DATA AVAILABILITY STATEMENT}

All relevant data are within the paper and its Supplementary Materials. The metabolomic data for this study can be found in the MetaboLights database (60) under Accession No. MTBLS2643 (http://www.ebi.ac.uk/metabolights/ MTBLS2643). The full dataset is also available from Tingting Zhou (tingtingchou@126.com).

\section{ETHICS STATEMENT}

The animal study was reviewed and approved by the Animal Experimentation Ethics Committee, Jiangnan University (License No: JN. No 20190930c1000120[232]).

\section{AUTHOR CONTRIBUTIONS}

SY and ZW: conception, design, data analysis, and interpretation. MG, MD, XW, and FY: administrative support. LG, LL, and YL: provision of study materials or patients. LF and TZ: collection and assembly of data. All authors manuscript writing, final approval of manuscript, read, and approved this manuscript.

\section{FUNDING}

This work was supported by the China National Natural Science Foundation (Grant 81800430) and Wuxi Municipal Health Commission scientific research project (M202044).

\section{ACKNOWLEDGMENTS}

We thank Prof. Iain C. Bruce for critical reading of the manuscript.

\section{SUPPLEMENTARY MATERIAL}

The Supplementary Material for this article can be found online at: https://www.frontiersin.org/articles/10.3389/fcvm. 2021.683859/full\#supplementary-material

3. Zhu Z, Wang P, Ma S. Metabolic hypertension: concept and practice. Front Med. (2013) 7:201-6. doi: 10.1007/s11684-013-0264-4

4. Granger JP, Schnackenberg CG. Renal mechanisms of angiotensin II-induced hypertension. Semin Nephrol. (2000) 20:417-25.

5. Long DA, Price KL, Herrera-Acosta J, Johnson RJ. How does angiotensin II cause renal injury? Hypertension (Dallas, Tex: 1979). (2004) 43:7223. doi: 10.1161/01.HYP.0000120964.22281.3e

6. Mashima Y, Konta T, Kudo K, Takasaki S, Ichikawa K, Suzuki K, et al. Increases in urinary albumin and beta2-microglobulin are independently associated 
with blood pressure in the Japanese general population: the Takahata Study. Hypertens Res. (2011) 34:831-5. doi: 10.1038/hr.2011.42

7. Naftilan AJ. The role of angiotensin II in vascular smooth muscle cell growth. J Cardiovasc Pharmacol. (1992) 20(Suppl. 1):S37-40. doi: 10.1097/00005344-199206201-00008

8. Puyó AM, Mayer MA, Giorgi S, Gómez AH, Peredo HA. Noradrenaline and angiotensin II modify vascular prostanoid release in fructose-fed hypertensive rats. Auton Autacoid Pharmacol. (2007) 27:161-5. doi: 10.1111/j.1474-8673.2007.00409.x

9. Foulquier S, Namsolleck P, Van Hagen BT, Milanova I, Post MJ, Blankesteijn WM, et al. Hypertension-induced cognitive impairment: insights from prolonged angiotensin II infusion in mice. Hypertens Res. (2018) 41:81727. doi: 10.1038/s41440-018-0090-9

10. Beyoglu D, Imbeaud S, Maurhofer O, Bioulac-Sage P, Zucman-Rossi J, Dufour JF, et al. Tissue metabolomics of hepatocellular carcinoma: tumor energy metabolism and the role of transcriptomic classification. Hepatology (Baltimore, Md). (2013) 58:229-38. doi: 10.1002/hep.26350

11. Patterson AD, Maurhofer O, Beyoglu D, Lanz C, Krausz KW, Pabst T, et al. Aberrant lipid metabolism in hepatocellular carcinoma revealed by plasma metabolomics and lipid profiling. Cancer Res. (2011) 71:6590600. doi: 10.1158/0008-5472.CAN-11-0885

12. Gika HG, Theodoridis GA, Plumb RS, Wilson ID. Current practice of liquid chromatography-mass spectrometry in metabolomics and metabonomics. $J$ Pharm Biomed Anal. (2014) 87:12-25. doi: 10.1016/j.jpba.2013.06.032

13. Theodoridis G, Gika HG, Wilson ID. Mass spectrometry-based holistic analytical approaches for metabolite profiling in systems biology studies. Mass Spectrom Rev. (2011) 30:884-906. doi: 10.1002/mas.20306

14. Want EJ, Wilson ID, Gika H, Theodoridis G, Plumb RS, Shockcor J, et al. Global metabolic profiling procedures for urine using UPLC-MS. Nat Protoc. (2010) 5:1005-18. doi: 10.1038/nprot.2010.50

15. Deshotels MR, Xia H, Sriramula S, Lazartigues E, Filipeanu CM. Angiotensin II mediates angiotensin converting enzyme type 2 internalization and degradation through an angiotensin II type I receptor-dependent mechanism. Hypertension (Dallas, Tex: 1979). (2014) 64:1368-75. doi: 10.1161/HYPERTENSIONAHA.114.03743

16. Zhou CX, Gan Y, Elsheikha HM, Chen XQ, Cong H, Liu Q, et al. Sulfadiazine sodium ameliorates the metabolomic perturbation in mice infected with Toxoplasma gondii. Antimicrob Agents Chemother. (2019) 63:e00312-19. doi: 10.1128/AAC.00312-19

17. Smith CA, O'Maille G, Want EJ, Qin C, Trauger SA, Brandon TR, et al. METLIN: a metabolite mass spectral database. Ther Drug Monit. (2005) 27:747-51. doi: 10.1097/01.ftd.0000179845.53213.39

18. Wishart DS, Feunang YD, Marcu A, Guo AC, Liang K, Vázquez-Fresno R, et al. HMDB 4.0: the human metabolome database for 2018. Nucleic Acids Res. (2018) 46:D608-17. doi: 10.1093/nar/gkx1089

19. Burlando B, Blanchini F, Giordano G. Loop analysis of blood pressure/volume homeostasis. PLoS Comput Biol. (2019) 15:e1007346. doi: 10.1371/journal.pcbi.1007346

20. Fu Z, Hu J, Zhou L, Chen Y, Deng M, Liu X, et al. (Pro)renin receptor contributes to pregnancy-induced sodium-water retention in rats via activation of intrarenal RAAS and $\alpha$-ENaC. Am J Physiol Renal Physiol. (2019) 316:F530-8. doi: 10.1152/ajprenal.00411.2018

21. Baños M, Arellano-Mendoza MG, Vargas-Robles H, Avila-Casado MC, Soto V, Romo E, et al. Relationship between angiotensin II receptor expression and cardiovascular risk factors in Mexican patients with coronary occlusive disease. Exp Mol Pathol. (2011) 91:478-83. doi: 10.1016/j.yexmp.2011.05.002

22. Marchesi C, Paradis P, Schiffrin EL. Role of the renin-angiotensin system in vascular inflammation. Trends Pharmacol Sci. (2008) 29:36774. doi: $10.1016 / j . t i p s .2008 .05 .003$

23. Johnson AW, Kinzenbaw DA, Modrick ML, Faraci FM. Smallmolecule inhibitors of signal transducer and activator of transcription 3 protect against angiotensin II-induced vascular dysfunction and hypertension. Hypertension (Dallas, Tex: 1979). (2013) 61:437-42. doi: 10.1161/HYPERTENSIONAHA.111.00299

24. Perry SF, Ellis K, Russell J, Bernier NJ, Montpetit C. Effects of chronic dietary salt loading on the renin angiotensin and adrenergic systems of rainbow trout (Oncorhynchus mykiss). Am J Physiol Regul Integr Comp Physiol. (2011) 301:R811-21. doi: 10.1152/ajpregu.00244.2011
25. Yatabe J, Yoneda M, Yatabe MS, Watanabe T, Felder RA, Jose PA, et al. Angiotensin III stimulates aldosterone secretion from adrenal gland partially via angiotensin II type 2 receptor but not angiotensin II type 1 receptor. Endocrinology. (2011) 152:1582-8. doi: 10.1210/en.2010-1070

26. Gao L, Yuan P, Zhang Q, Fu Y, Hou Y, Wei Y, et al. Taxifolin improves disorders of glucose metabolism and water-salt metabolism in kidney via PI3K/AKT signaling pathway in metabolic syndrome rats. Life Sci. (2020) 263:118713. doi: 10.1016/j.lfs.2020.118713

27. Fyhrquist F, Metsärinne K, Tikkanen I. Role of angiotensin II in blood pressure regulation and in the pathophysiology of cardiovascular disorders. J Hum Hypertens. (1995) 9(Suppl. 5):S19-24.

28. Hu Z, Wang Z, Wu H, Yang Z, Jiang W, Li L, et al. Ang II enhances noradrenaline release from sympathetic nerve endings thus contributing to the up-regulation of metalloprotease- 2 in aortic dissection patients' aorta wall. PLoS ONE. (2013) 8:e76922. doi: 10.1371/journal.pone.0076922

29. Boegehold MA, Drenjancevic I, Lombard JH. Salt, angiotensin II, superoxide, and endothelial function. Comp Physiol. (2015) 6:215-54. doi: 10.1002/cphy.c150008

30. Schmidt-Ott KM, Kagiyama S, Phillips MI. The multiple actions of angiotensin II in atherosclerosis. Regul Pept. (2000) 93:65-77. doi: 10.1016/S0167-0115(00)00178-6

31. Cheema MU, Pluznick JL. Gut microbiota plays a central role to modulate the plasma and fecal metabolomes in response to angiotensin II. Hypertension (Dallas, Tex: 1979). (2019) 74:184-93. doi: 10.1161/HYPERTENSIONAHA.119.13155

32. Ye L, Ding F, Zhang L, Shen A, Yao H, Deng L, et al. Serum apelin is associated with left ventricular hypertrophy in untreated hypertension patients. J Transl Med. (2015) 13:290. doi: 10.1186/s12967-015-0635-5

33. Wang L, Zhang YL, Lin QY, Liu Y, Guan XM, Ma XL, et al. CXCL1-CXCR2 axis mediates angiotensin II-induced cardiac hypertrophy and remodelling through regulation of monocyte infiltration. Eur Heart J. (2018) 39:181831. doi: 10.1093/eurhearti/ehy085

34. Schroeder AP, Sihm I, Mørn B, Thygesen K, Pedersen EB, Lederballe O. Influence of humoral and neurohormonal factors on cardiovascular hypertrophy in untreated essential hypertensives. Am J Hypertens. (1996) 9:207-15. doi: 10.1016/0895-7061(95)00352-5

35. Caillon A, Mian MOR, Fraulob-Aquino JC, Huo KG, Barhoumi $\mathrm{T}$, Ouerd S, et al. $\gamma \delta \mathrm{T}$ cells mediate angiotensin II-induced hypertension and vascular injury. Circulation. (2017) 135:215562. doi: 10.1161/CIRCULATIONAHA.116.027058

36. Li XC, Zhu D, Chen X, Zheng X, Zhao C, Zhang J, et al. Proximal tubulespecific deletion of the NHE3 $(\mathrm{Na}+/ \mathrm{H}+$ exchanger 3$)$ in the kidney attenuates ang II (angiotensin II)-induced hypertension in mice. Hypertension (Dallas, Tex: 1979). (2019) 74:526-35. doi: 10.1161/HYPERTENSIONAHA.119. 13094

37. Wysocki J, Ye M, Rodriguez E, González-Pacheco FR, Barrios C, Evora $\mathrm{K}$, et al. Targeting the degradation of angiotensin II with recombinant angiotensin-converting enzyme 2: prevention of angiotensin II-dependent hypertension. Hypertension (Dallas, Tex: 1979). (2010) 55:90-8. doi: 10.1161/HYPERTENSIONAHA.109.138420

38. Cheung BM, Li C. Diabetes and hypertension: is there a common metabolic pathway? Curr Atheroscler Rep. (2012) 14:160-6. doi: 10.1007/s11883-012-0227-2

39. Petrie JR, Guzik TJ, Touyz RM. Diabetes, hypertension, and cardiovascular disease: clinical insights and vascular mechanisms. Can J Cardiol. (2018) 34:575-84. doi: 10.1016/j.cjca.2017.12.005

40. Shi Z, Abou-Samra AB. Association of low serum magnesium with diabetes and hypertension: findings from Qatar Biobank study. Diabetes Res Clin Pract. (2019) 158:107903. doi: 10.1016/j.diabres.2019.107903

41. Geiss LS, Rolka DB, Engelgau MM. Elevated blood pressure among U.S. adults with diabetes, 1988-1994. Am J Prevent Med. (2002) 22:428. doi: 10.1016/S0749-3797(01)00399-3

42. Jones JR, Barrick C, Kim KA, Lindner J, Blondeau B, Fujimoto Y, et al. Deletion of PPARgamma in adipose tissues of mice protects against high fat diet-induced obesity and insulin resistance. Proc Natl Acad Sci USA. (2005) 102:6207-12. doi: 10.1073/pnas.0306743102

43. Lazar MA. Reversing the curse on PPAR $\gamma$. J Clin Investig. (2018) 128:22024. doi: 10.1172/JCI121392 
44. Xu L, Ma X, Verma NK, Wang D, Gavrilova O, Proia RL, et al. Ablation of PPAR $\gamma$ in subcutaneous fat exacerbates age-associated obesity and metabolic decline. Aging Cell. (2018) 17:12721. doi: 10.1111/acel.12721

45. Guo S, Som AT, Arai K, Lo EH. Effects of angiotensin-II on brain endothelial cell permeability via PPARalpha regulation of para- and trans-cellular pathways. Brain Res. (2019) 1722:146353. doi: 10.1016/j.brainres.2019.146353

46. Haussler MR, Haussler CA, Jurutka PW, Thompson PD, Hsieh JC, Remus LS, et al. The vitamin $\mathrm{D}$ hormone and its nuclear receptor: molecular actions and disease states. J Endocrinol. (1997) 154:S57-73.

47. Chandra V, Wu D, Li S, Potluri N, Kim Y, Rastinejad F. The quaternary architecture of RAR $\beta-R X R \alpha$ heterodimer facilitates domain-domain signal transmission. Nat Commun. (2017) 8:868. doi: 10.1038/s41467-017-00981-y

48. Lalloyer F, Pedersen TA, Gross B, Lestavel S, Yous S, Vallez E, et al. Rexinoid bexarotene modulates triglyceride but not cholesterol metabolism via genespecific permissivity of the RXR/LXR heterodimer in the liver. Arterioscler Thromb Vasc Biol. (2009) 29:1488-95. doi: 10.1161/ATVBAHA.109.189506

49. Song CS, Echchgadda I, Baek BS, Ahn SC, Oh T, Roy AK, et al. Dehydroepiandrosterone sulfotransferase gene induction by bile acid activated farnesoid X receptor. J Biol Chem. (2001) 276:42549-56. doi: 10.1074/jbc.M107557200

50. Chesney RW, Han X. Differential regulation of TauT by calcitriol and retinoic acid via VDR/RXR in LLC-PK1 and MCF-7 cells. Adv Exp Med Biol. (2013) 776:291-305. doi: 10.1007/978-1-4614-6093-0_27

51. Harrus D, Déméné H, Vasquez E, Boulahtouf A, Germain P, Figueira AC, et al. Pathological interactions between mutant thyroid hormone receptors and corepressors and their modulation by a thyroid hormone analogue with therapeutic potential. Thyroid. (2018) 28:1708-22. doi: 10.1089/thy.2017.0551

52. Plutzky J. The PPAR-RXR transcriptional complex in the vasculature: energy in the balance. Circ Res. (2011) 108:100216. doi: 10.1161/CIRCRESAHA.110.226860

53. Tsukahara T, Tsukahara R, Fujiwara Y, Yue J, Cheng Y, Guo H, et al. Phospholipase D2-dependent inhibition of the nuclear hormone receptor PPARgamma by cyclic phosphatidic acid. Mol Cell. (2010) 39:42132. doi: 10.1016/j.molcel.2010.07.022

54. Ziouzenkova O, Orasanu G, Sharlach M, Akiyama TE, Berger JP, Viereck J, et al. Retinaldehyde represses adipogenesis and diet-induced obesity. Nat Med. (2007) 13:695-702. doi: 10.1038/nm1587
55. Atikuzzaman M, Koo OJ, Kang JT, Kwon DK, Park SJ, Kim SJ, et al. The 9-cis retinoic acid signaling pathway and its regulation of prostaglandin-endoperoxide synthase 2 during in vitro maturation of pig cumulus cell-oocyte complexes and effects on parthenogenetic embryo production. Biol Reprod. (2011) 84:1272-81. doi: 10.1095/biolreprod.110.0 86595

56. Duvic M, Hymes K, Heald P, Breneman D, Martin AG, Myskowski P, et al. Bexarotene is effective and safe for treatment of refractory advanced-stage cutaneous T-cell lymphoma: multinational phase II-III trial results. J Clin Oncol. (2001) 19:2456-71. doi: 10.1200/JCO.2001.19.9.2456

57. Yoshida Y, Umeno A, Akazawa Y, Shichiri M, Murotomi K, Horie M. Chemistry of lipid peroxidation products and their use as biomarkers in early detection of diseases. J Oleo Sci. (2015) 64:347-56. doi: 10.5650/jos.ess14281

58. Oram JF, Vaughan AM, Stocker R. ATP-binding cassette transporter A1 mediates cellular secretion of alpha-tocopherol. J Biol Chem. (2001) 276:39898-902. doi: 10.1074/jbc.M106984200

59. Huesca-Gómez C, Torres-Paz YE, Martínez-Alvarado R, FuentevillaÁlvarez G, Del Valle-Mondragón L, Torres-Tamayo M, et al. Association between the transporters ABCA1/G1 and the expression of miR$33 \mathrm{a} / 144$ and the carotid intima media thickness in patients with arterial hypertension. Mol Biol Rep. (2020) 47:1321-9. doi: 10.1007/s11033-019-0 5229-0

60. Haug K, Cochrane K, Nainala VC, Williams M, Chang J, Jayaseelan KV, et al. MetaboLights: a resource evolving in response to the needs of its scientific community. Nucleic Acids Res. (2020) 48:D440-4. doi: 10.1093/nar/gkz1019

Conflict of Interest: The authors declare that the research was conducted in the absence of any commercial or financial relationships that could be construed as a potential conflict of interest.

Copyright (c) 2021 Yang, Wang, Guo, Du, Wen, Geng, Yu, Liu, Li, Feng and Zhou. This is an open-access article distributed under the terms of the Creative Commons Attribution License (CC BY). The use, distribution or reproduction in other forums is permitted, provided the original author(s) and the copyright owner(s) are credited and that the original publication in this journal is cited, in accordance with accepted academic practice. No use, distribution or reproduction is permitted which does not comply with these terms. 